\title{
Research with school students: four innovative methods used to explore effective teaching
}

\author{
Jessica Faye Heal* \\ Teach First and the University of Manchester, UK \\ *Correspondence: iheal@teachfirst.org.uk
}

\begin{abstract}
This article outlines the need for innovative research methods and discusses four approaches employed within an educational setting to enhance how students between the ages of 5-18 years old engage in research exploring effective teaching. It draws on upon Article 12 of the United Nations Convention on the Rights of the Child, focussing on the 'space' in which the research is conducted and the 'voice' of the child. Through two techniques to scaffold the semi-structured interview, a childled classroom tour and a 'draw-and-tell' style method, the researcherparticipant power imbalance is interrupted. Their efficacy to disrupt lies in the following unifying characteristics: providing familiarity to the student, situating the student as an expert and giving the student choice.
\end{abstract}

Peer review: This article has been subject to a double blind peer review process

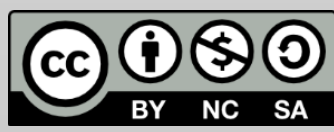

C Copyright: The Authors. This article is issued under the terms of the Creative Commons Attribution NonCommercial Share Alike License, which permits use and redistribution of the work provided that the original author and source are credited, the work is not used for commercial purposes and that any derivative works are made available under the same license terms.
Keywords: innovative research methods; young people; education; interviews; draw and tell; child-led; child rights, primary, secondary, student voice

\section{Introduction}

As a doctoral researcher, ex-language teacher and full time qualitative researcher at Teach First, students are at the heart of what I do and the reason I do what I do. Since my undergraduate days, I have been passionate about bringing unheard voices to the fore, and for the last seven years I have been working with young people from the poorest backgrounds that our society consistently ill-considers and ignores.

The opinions and perceptions of these students are of central importance to how we recruit, train and support our teachers at Teach First. This article, adapted from the Inequality in Education - Innovative conference presentation, highlights why the student voice is such an important issue and then outlines four methods that enhance how students participate in our research. Although conducted within an educational setting, these 
methods are transferable for use with children and young people more broadly and the citations and language reflect this. Working in compliance with Article 12 of the United Nations Convention Rights of a Child, these methods aim to disrupt the interviewee-interviewer power balance by providing choice, ownership and familiarity. These methods are arguably effective in supporting students to make informed and valuable contributions to research into effective teaching.

\section{The project overview}

Over the past year, interviews have been conducted with 124 students, 21 teachers and 20 mentors in order to explore what appears to be making their classroom a successful learning environment. The teachers are purposively sampled through a combination of data and recommendations from those who work closely with them. They, in turn, then put forward a selection of higher, middle and lower attaining pupils for us to work with. After data collection, a thematic analysis is conducted and the findings from this inform how we recruit, train and support new teachers.

However, there is a tension in using the word 'effective' - this positivist term sits quite uneasily within our qualitative, more intepretivist research. This is a product of our industry, conducting researching within a sector where 'impact', and the measurement of it, accounts for substantial funding income. Within this institutional imperative, we aim to craft a space within which valuable qualitative research can be carried out. This is through the loose interpretation of the word 'effective' to mean 'standing out as a teacher that the education community is able to learn from'. To explore which elements of teacher practice should be learnt from, it is paramount to seek to understand what students feel they most benefit from - they are the ones currently experiencing a variety of different classrooms and are therefore most attuned to how they learn.

\section{Why we need different research methods}

The UNCRC Article 12 states all young people have the right to be heard, and that their voice must be given 'due weight' in matters which concern them. This contributes to this paradigm shift in research design in social science, moving from merely respecting participants to a considered, contextual and culturally sensitive approach (Suinn, 2006). In line with this development, the academic community has an ethical obligation to uphold this paradigm when conducting research with students. 
Designing research which works within the principles of article 12 has been explored in depth by Lundy who posits that you need to go beyond the stated requirements in order to fulfil them, ensuring students:

- Can express their voice through whichever medium they prefer

- Have a safe and inclusive space to form and express a view

- Have an audience that will listen to the view

- Hold views which will be of influence and acted upon

(2007; 2013: 2)

It is our responsibility to create an environment to ensure students feel empowered: conducting research with students, not about them (Thompson, 2009). This comes from the premise that 'we desire to position children as social actors who are subjects, rather than objects of inquiry' (Christensen and James, 2008: 2). The work of the researcher can be compared to work of a gallery curator - it is the students who are the masters and experts of their situation and the role of the researcher is to ensure the gallery doors are open and it is teeming with an audience who leave affected. This is where the four methods come in, facilitating the creation of these oeuvres.

\section{Four approaches to support student voice}

The methods below focus on supporting the 'voice' and 'space' elements of Lundy's Article 12 framework (2013). Methods one and three scaffold the traditional semi-structured interview through a pre-task and using student work as a prompt, method two is an exploratory child-led tour of the classroom and the last is a creative research method. Looking beneath the surface of each method, they share the following qualities:

-providing students choice

-enabling student ownership

-structuring the interactions within familiarity

-disrupting the interviewer-interviewee power balance

Redressing the power balance in an interview situation is a key issue when conducting qualitative research because the power relations that emerge in interviews are embedded within the data they produce

(Briggs, 2003). With young people and vulnerable groups, this is an even greater issue because the imbalance between interviewer-interviewee is exacerbated (Morrow and Richards, 1996; Edger and Fingerson, 1999). 
Lincoln and Guba (1985), Denzin and Lincoln (2000) and Flick (2002) all highlight the need for researchers to be vigilant to ensure that the participants feel comfortable to speak in a voice that is authentic.

Logistically, interviewing students generally takes place in pairs. This not only acts as a physical shift in the power ratio, 2 interviewees: 1 interviewer, but also reduces participant discomfort and helps them to build on ideas as a pair. This has been shown to create an environment where participants are more animated and give more substantiated, nuanced and comprehensive answers (Lohm and Kirpitchenko 2014).

\section{Pre-interview task}

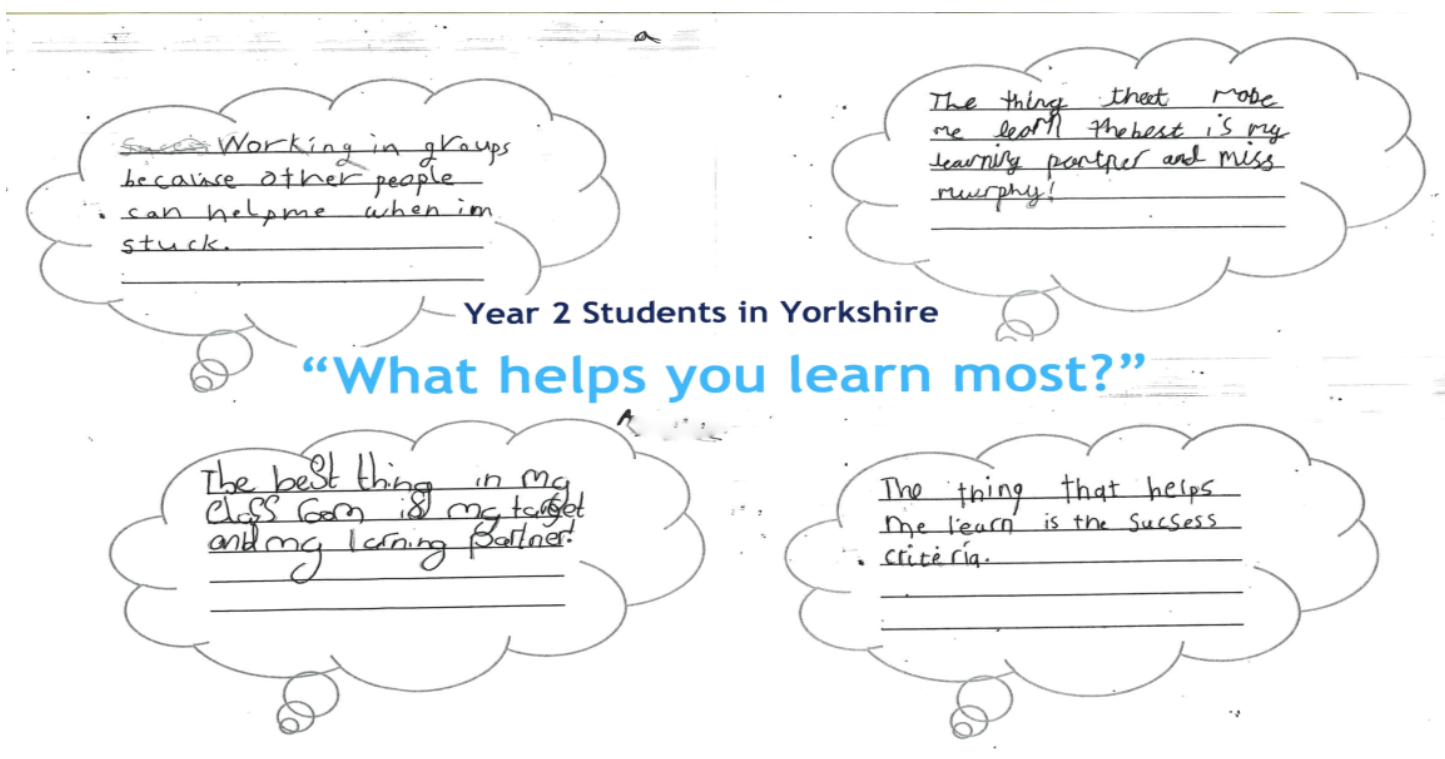

Figure i: Four examples of student learning bubbles

The day before the visit, a Year 2 Class in Yorkshire (ages 6-7) were asked to fill in a learning bubble, answering the question 'what helps you learn most?'. Learning bubbles were a familiar classroom tool, which the teacher used regularly to help the students reflect on their learning; this meant it was a medium of communication they already knew how to engage with. It should be noted that with any regular classroom activity considering 'school genres', implicit rules and regulations could be acting upon the students' engagement in the activity (Moss, 1989).

The students' responses were collated and used to inform the research in two ways. Firstly, they supported the group interview as using pedagogic language familiar to the students mitigated issues highlighted by Sarah Punch; when adults and children use a vocabulary or language style 
which is unfamiliar to the other (2002). This communal understanding of language allows both the interviewer and students to access the conversation. For instance, the extract below shows students explaining a particular concept they had referenced on their learning bubble.

JFH: Okay, so one thing it says here is that your learning partner helps you learn. What is a learning partner?

Trey: It's a partner that helps you learn. If you're stuck on anything, you can't do it by yourself, then you have to go with a partner.

Jenny: They help you a lot.

Leyla: If you're stuck, you ask your learning partner, and if your learning partner is stuck with you asking a question, you ask the teacher instead.

Trey: Everyone's in it together, you're not by yourself.

This interview extract shows the underlying feelings students have around their class ethos and the sense of security it affords. This method gives students time to prepare, is sensitive to their experience and empowers them to talk about the situation (Gallagher, 2008).

Fundamentally, it gives them ownership of the discussion by building on their previous learning bubble answers. A secondary benefit of the preinterview task is that it enables the collation of answers from the whole class, providing a broader snapshot of how the class feels about their learning. It's striking that two thirds of the class, in this example, gave an answer which was not their teacher; suggesting that certain pedagogical strategies could help to build student independence. 


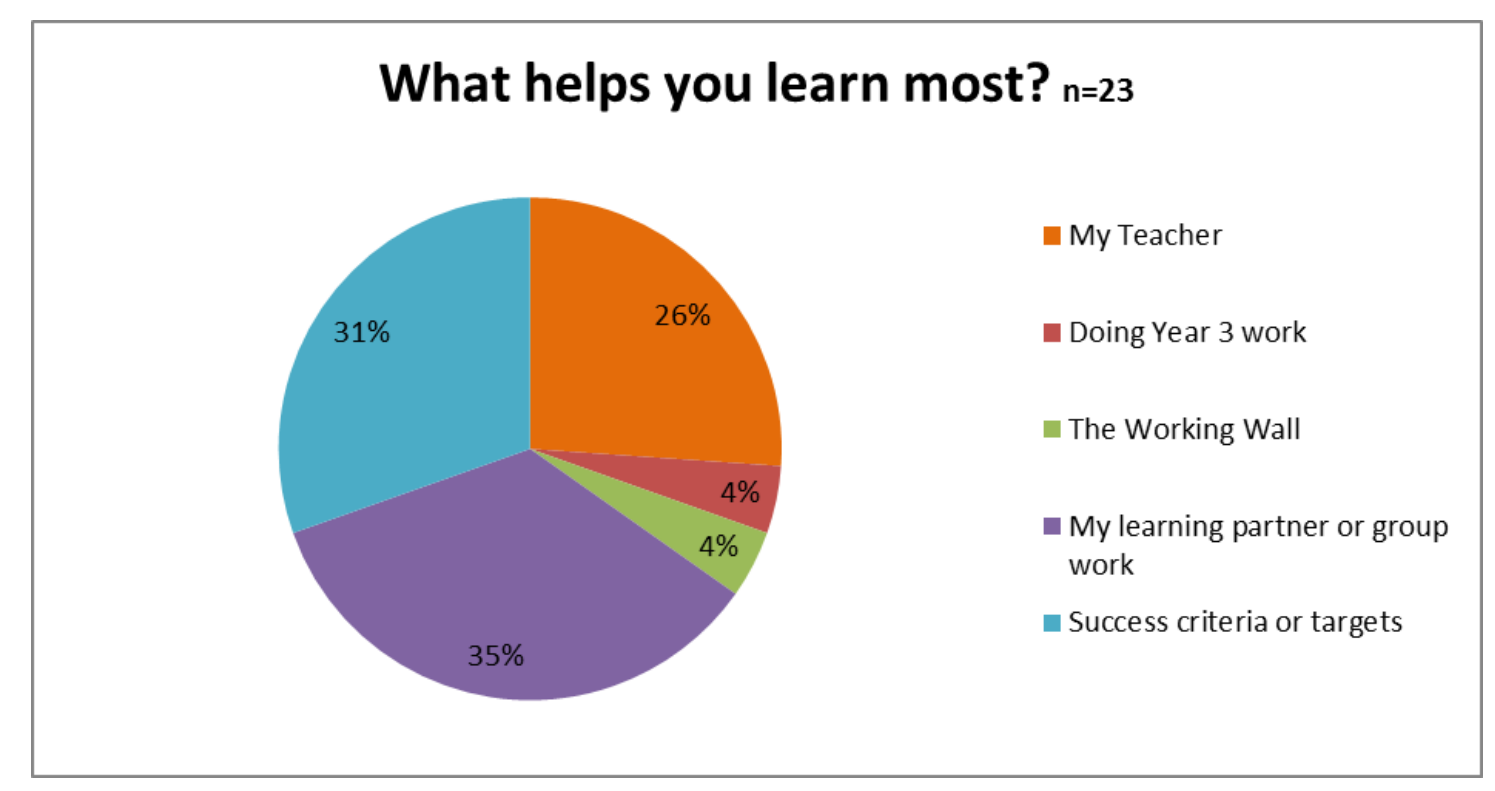

Figure ii: Whole class response to the question 'what helps you learn most?'

\section{Classroom Environment}

'The use of child led tours privileges the ways that young children communicate, in active, visual ways' (Clark, 2010: 117).

A student from the same Year 2 class conducted a tour of his classroom, the researcher then films the classroom displays that helped the student learn most: the 'progress train' on the display board [figure iii] and his target stuck onto his table [figure iv]. The student had ownership over the data collected, an expert within a familiar environment who had the choice of where to go and what to discuss. The tour was fully child-led and, although Trey was not operating the camera himself, he directed where it should be pointed. This approach opens up a new communicative space which provides a window into the classroom through the eyes of a student. This child-led approach reveals a new angle for teachers and educationalists to understand how students perceive and value their environment (Clark, 2010: 122). 


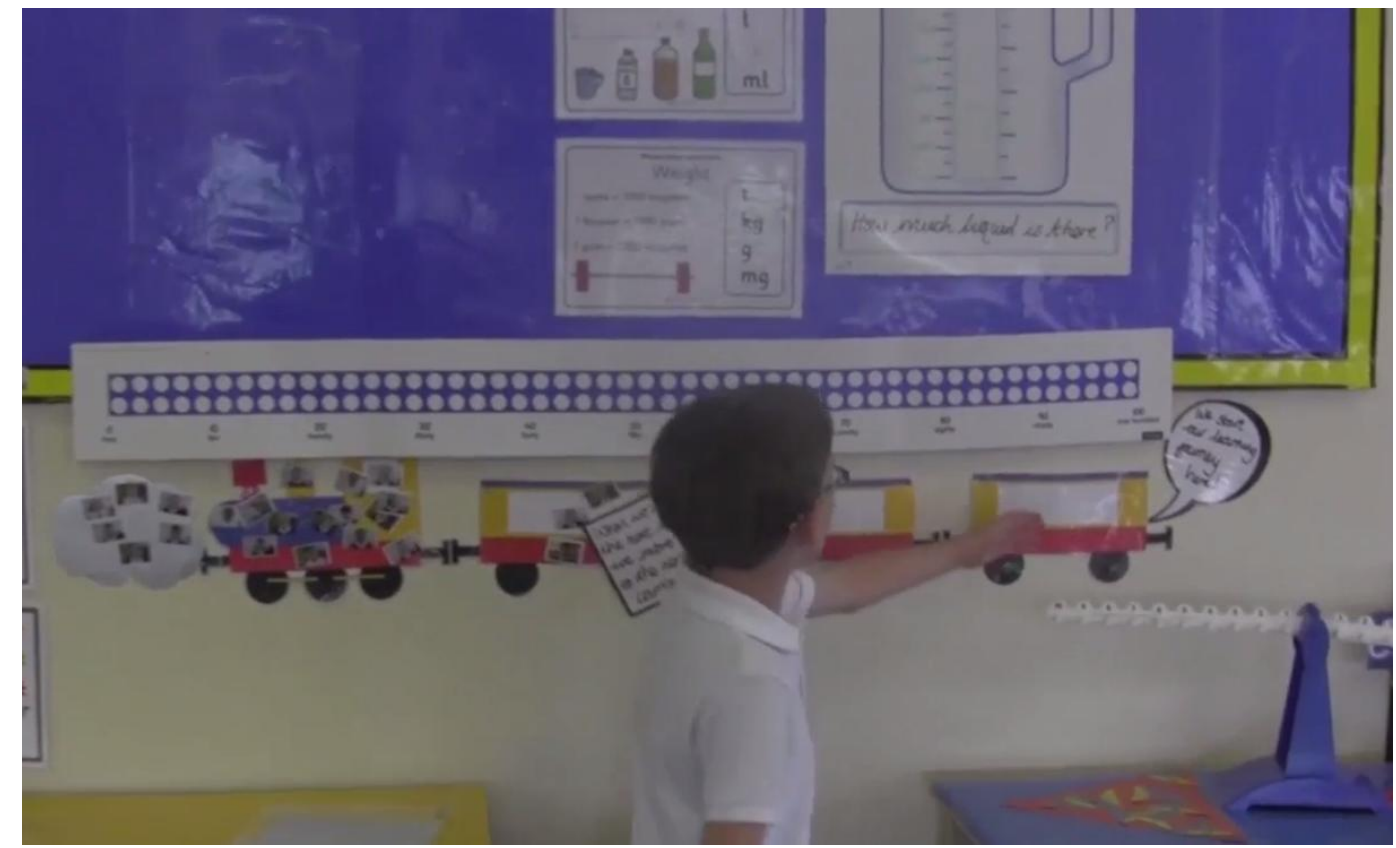

Figure iii: Screen shot of the 'progress train' which Trey wanted to show me because it helps him learn if he knows where he is on the train.

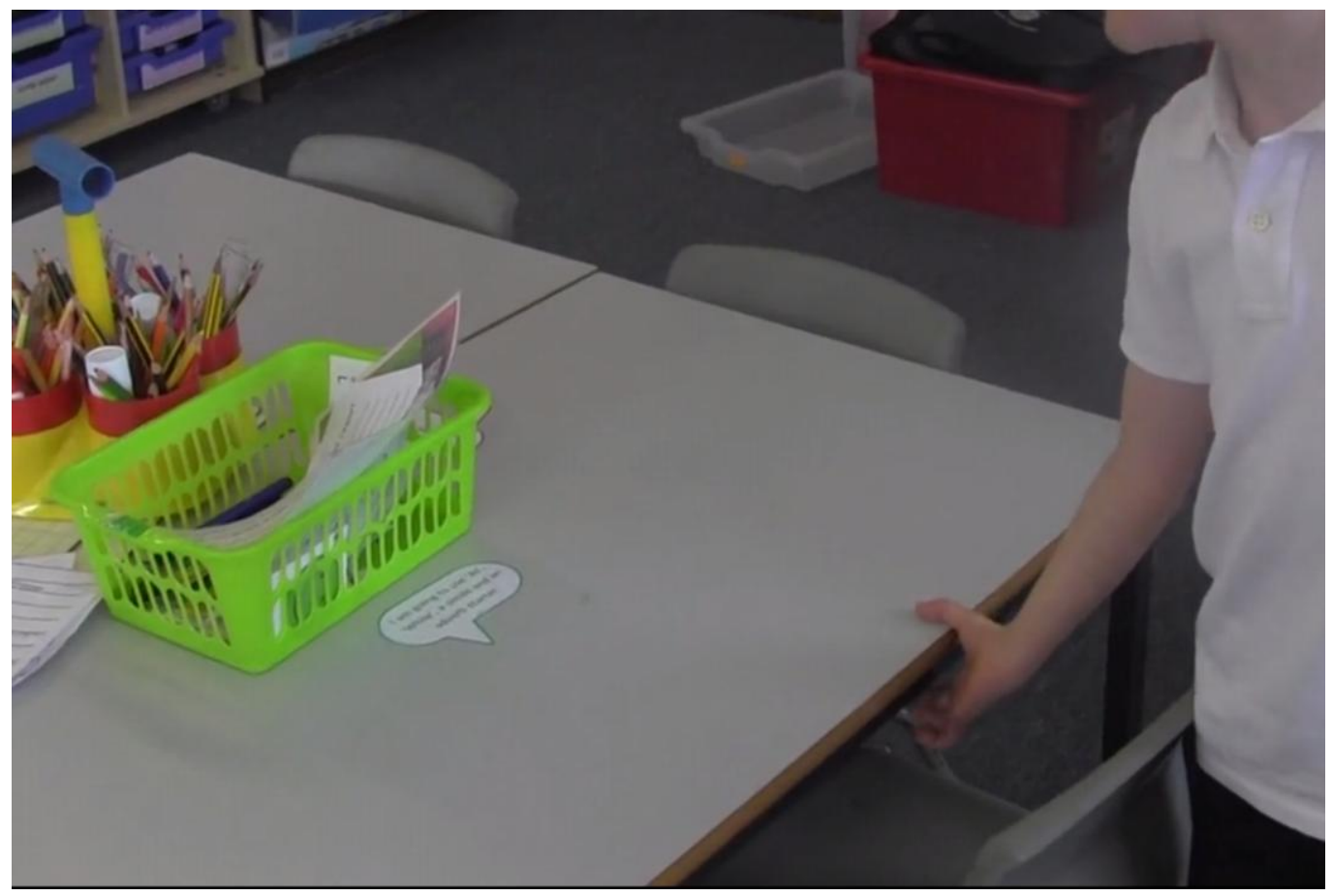

Figure iv: Screen shot from filmed class tour, this image shows Trey discussing his target and how he finds it useful as a reminder of what to focus on

The classroom tour, pre-interview task and semi-structured interview combined with classroom footage of teaching and learning, is reminiscent of the multi-method Mosaic Approach developed by Clark and Moss (2004). The multi-faceted method is designed to help adult 
researchers who wish to listen to young children's perspectives by capitalising upon young children's competencies (Kay, 2009). It enables a broader and deeper picture of the classroom to be drawn, giving us multiple materials to both analyse and then share with those who can learn and act upon it.

\section{Student work}

School work has be found to be a useful prompt for secondary school age students during the semi-structured interview. The use of student work developed the interview into a more exploratory conversation through revealing deeper reflections, perceptions and subjective understandings of student experience. The example below, featuring two Year 7 students (ages 11-12) discussing how their teacher marks their books, highlights how it can 'uncover unarticulated informant knowledge' (Johnson and Weller, 2001: 491).

Amy: $\quad$ She gives us comments and because on mine, I spelt something wrong and I didn't do all of the accents on the tops of the words, she will write comments like, be careful with spellings and try and make your sentences longer and don't forget your accents. She will give you levels...She will give you bit to fill in...You have to do how you felt about your work like circle them and explain how you felt. Then Miss put I did good work and she didn't put spelling that much she just put punctuation because I miss a lot of the accents out.

Ben: $\quad . .$. Once we know what we are struggling on we can improve it and that we need to improve on that and that helps us get our work to be almost perfect.

JFH: $\quad$ That is really interesting, because you enjoy the fun stuff but that is not a fun thing but like you said it helps you. Can you explain that in a way that? What could a new teacher learn from that?

Ben: $\quad$ Try to use comment much as you can because if someone in your class is struggling...

Ben: $\quad$...Also it helps because say that someone is struggling in class and they don't want to speak out loud to the teacher, they can write it down like a small message. Once the teacher has got it they can think - they will look everyone is work and if most people put the same thing she has then got like a lesson plan that we can do. 


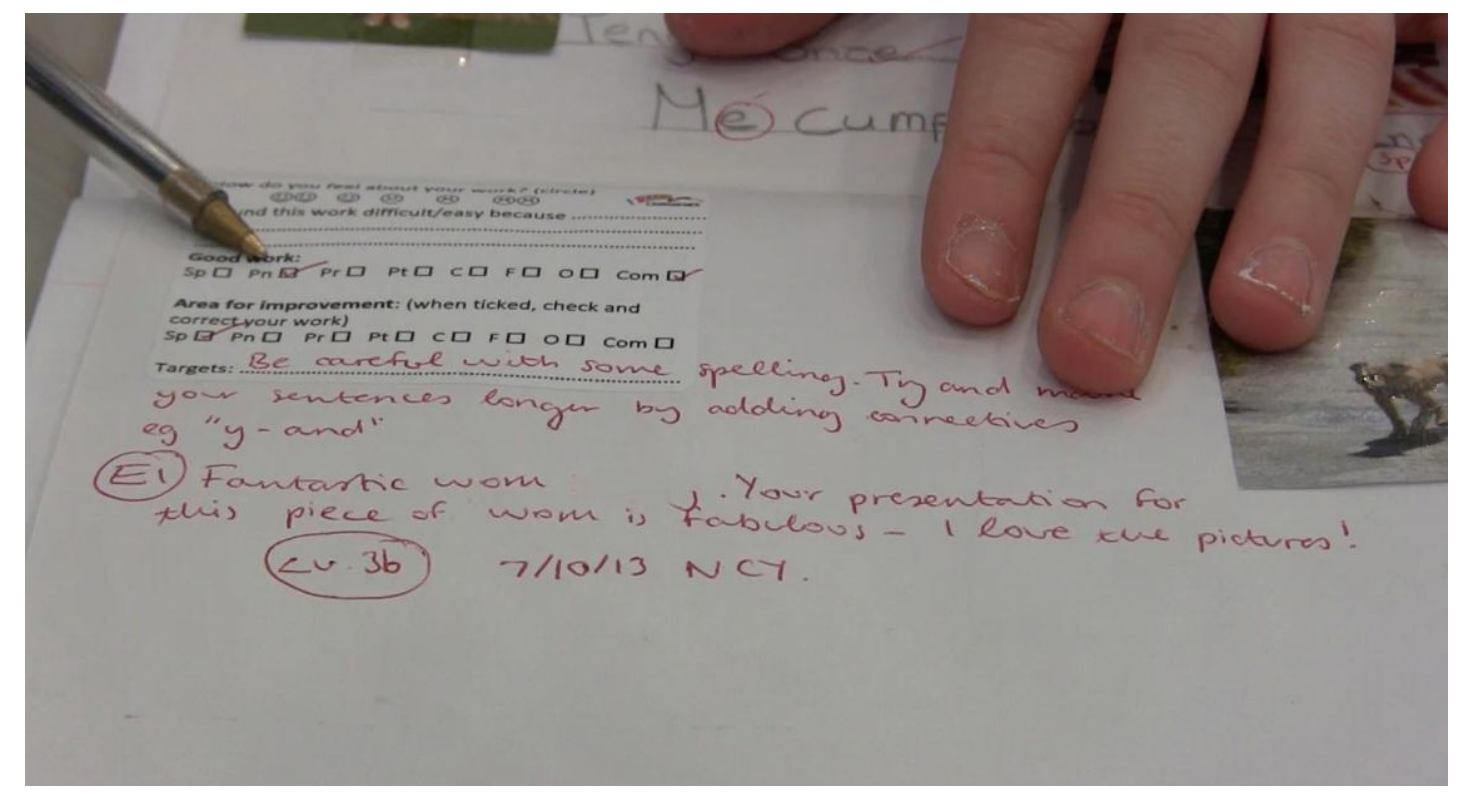

Figure v: Screen shot from interview of students discussing how their work is marked by the teacher

The conversation veers into deeper personal reflections, such as how they improve and how the teacher has reduced the discomfort caused by asking for help within the classroom setting. This method, although logistically different, acts in a similar way to the pre-interview task approach. It acts to redistribute the power balance between interviewer and interviewee by centering the conversation on an item that is familiar to the students and related to their personal experience, which enables them to confidently be experts. These methods, however, rely on a key factor: students feeling comfortable enough to overcome the power imbalance of talking to a relative stranger and, in some cases, on camera.

This last section will move onto discuss a method employed to be inclusive of those who are keen to express themselves through a different medium.

\section{Draw and tell}

Alongside other creative methods, draw and tell was developed in order to maximise student participation in research by offering an alternative to traditional data collection instruments. Emerging in an early form as 'draw and write' in the health research field in 1972, it was noted six and seven year olds were able to better draw their feelings and emotions, than articulate them (Wetton, 1999).

The draw and tell method has been employed with Primary students who do not feel comfortable talking with us. These pictures below are 
snapshots from a drawing created by Amaan, a Year 3 (ages 7-8) student from Birmingham, who was sat on the lower attaining table. Amaan was very shy and uncommunicative so I asked if he could draw a picture of his classroom and what he likes about it. Once he began drawing, I then asked 'can you explain this to me?' about each part of his picture as he drew, noting down his account verbatim. I then annotated his drawing with his explanations.

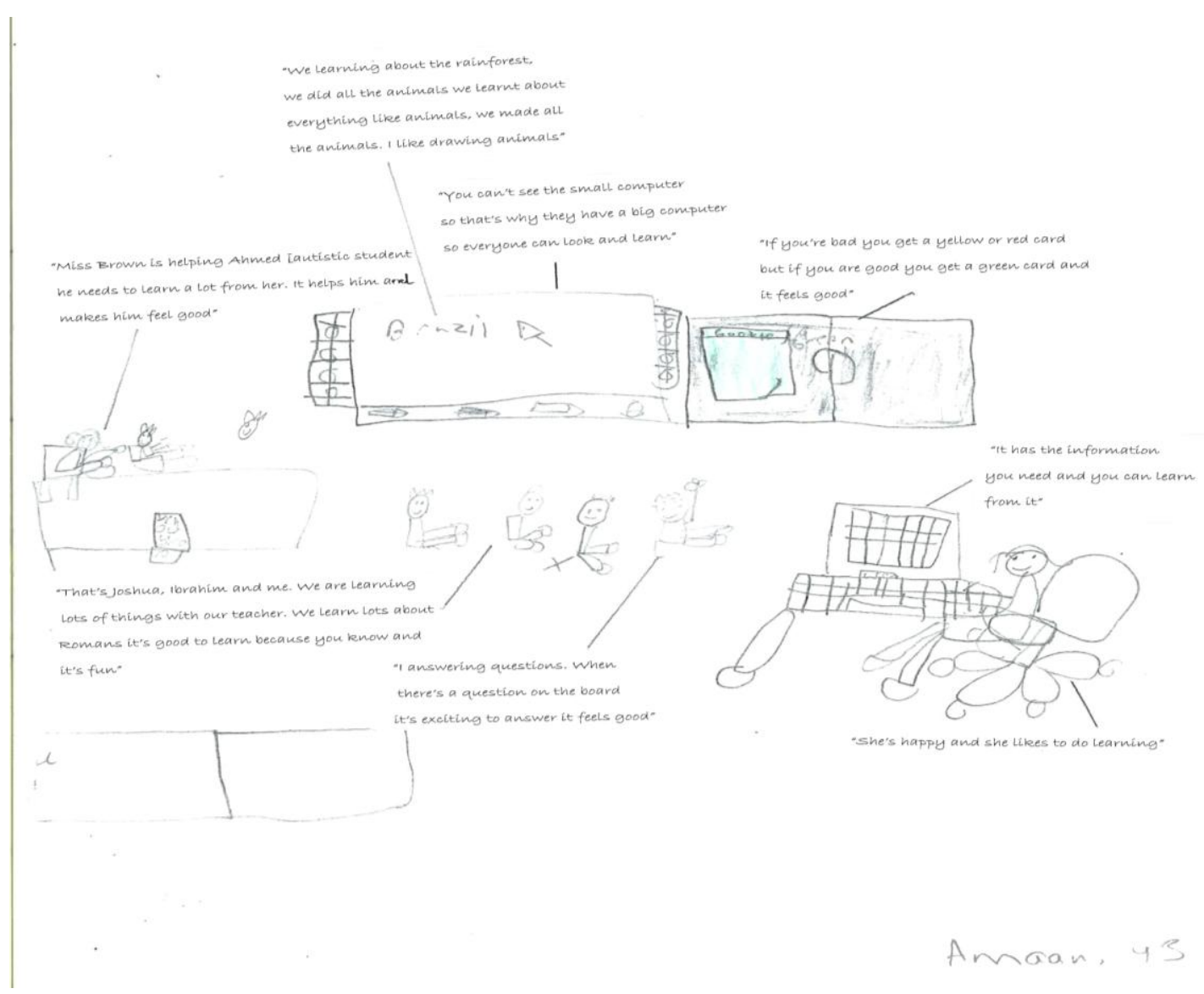

Figure vi: Year 3 Student draws their class and explains each picture

This method is particularly effective in allowing students to take time to think, building their answer in stages rather than needing to provide an immediate response (Gauntlett, 2004). As Angell stated, this approach goes some way to equalising the 'power imbalances' between adult researchers and children: as it offers 'each child an opportunity to subtly negotiate their own level of participation' (2014: 10).

\section{Conclusion}

'We tried to make the children experts in their own lives, and to inform them that this was the case. Many of the children 
were clearly unused to being regarded as the most important sources of information about their own lives in this waycertainly by an adult they hardly knew' (Langsted 1994: 35)

It is within these drawings, interviews and tours that I hope our research goes beyond Article 12 in providing the opportunity for all students irrespective of any measure or label - to influence their experience and the experience of other students across the UK.

The data we create with students has become more nuanced and powerful in its ability to influence through having the following qualities:

-providing students choice

-enabling student ownership

-structuring it within familiarity

-disrupting the interviewer-interviewee power balance

Whatever shape the method takes, if it considers these elements it can make a valid contribution to the students, the researcher and the organisation it aims to influence. Using these methods has provided accessible and realistic representations of student experience and has been used in analysis to enhance how teachers understand students and what they perceived as important. It brings the classroom to the organisation in such a measure that traditional interview copy cannot compete.

The four methods outlined aim to be a tool for researchers to scaffold their approach to support and situate students as the experts of their situation. The more students are empowered, the better the data and therefore the easier it becomes for this voice to influence policy and strategy. And, just like the classroom pedagogy, the more time you invest in thinking about the students you want to work with, the more they will invest in you.

\section{Acknowledgments}

Thank you to Teach First and the University of Manchester for advice and support and to all the students and teachers who welcomed me into their classrooms. Lastly I'm grateful to Siobhan Dytham and Carli Rowell for organising such an interesting conference and giving me the opportunity to present. 
List of Illustrations and Graphs
i. Student Learning Bubbles
ii. Pie chart of 'What helps you learn most?'
iii. Screen shot from video of classroom tour
iv. Screen shot from video of classroom tour
v. Screen shot of student work
vi. Drawing from interview 'what's your class like?'

\section{References}

Angell, C., Alexander, J., and Hunt, J. A. (2014), 'Draw, write and tell': A literature review and methodological development on the 'draw and write' research method, Journal of Early Childhood Research, August, 112

Briggs, C. (2003), 'Interviewing, Power/Knowledge and Social Inequality' in Jaber F. Gubrium, and James A. Holstein (eds), Postmodern Interviewing, Thousand Oaks: Sage, pp. 242-55

Christensen, P., \& James, A. (Eds.). (2008). Research with children: Perspectives and practices. Abingdon: Routledge.

Clark, A. (2004), 'The Mosaic Approach and Research with Young Children', in Lewis. V., Kellett, M., Robinson, C., Fraser, S., and S. Ding (Eds), The Reality of Research with Children and Young People. London: Open University pp. 142-161

Clark, A. (2010), 'Young children as protagonists and the role of participatory, visual methods in engaging multiple perspectives', American Journal of Community Psychology, 46(1-2), 115123

Denzin, N.K. and Lincoln, Y.S., (2000), Handbook of Qualitative Research, 2nd Edition. London: Sage.

Flick, U. (2002), An Introduction to Qualitative Research, London: Sage. Gallagher, M,, (2008), 'Data Collection and Analysis' in Tisdall, K., Davis, J. M., and Gallagher, M. (eds). Researching with children and young people: Research design, methods and analysis, London: Sage, pp. 65-77 
Gauntlett D., (2004) Using new creative visual research methods to understand the place of popular media in people's lives. Paper presented at the IAMCR, Porto Alegre, Brazil, 25-30 July, 2004

Johnson, J, and Weller, S., (2001), '24 Elicitation Techniques for Interviewing', in Jaber F. Gubrium, and James A. Holstein (eds), Handbook of Interview Research, Thousand Oaks: Sage, pp. 491-515,

Kay, E., Tisdall, M., Davis, J.M., and Gallagher, M (2009), 'Glossary of Terms', Researching with children and young people: Research design, methods and analysis, London: Sage, pp. 223-31

Langsted, O., (1994). 'Looking at quality from the child's perspective', In Moss, P., \& Pence, A., (Eds.), Valuing quality in early childhood services: New approaches to defining quality (pp. 28-42). London: Paul Chapman.

Lincoln, Y.S. Guba, E.G., (1985), Naturalistic Enquiry. London: Sage.

Lohm, D. and Kirpitchenko, L. (2014), 'Interviewing Pairs: Discussions on Migration and Identity', in Research Methods Cases, London: Sage

Lundy, L., (2007), 'Voice is not enough: Conceptualising Article 12 of the United Nations Convention the Rights of the Child', British Educational Research Journal, 33(6): 927-942

Lundy, L and Welty, E., (2013), 'A children's rights-based approach to involving children in decision making', Journal of Science Communication, 12(03), pp. 1-5

Moss, G., (1989), Un/Popular Fictions. London: Virago.

Morrow, V., and Richards, M., (1996), 'The ethics of social research with children: an overview', Children \& Society 10: 90-105.

Punch, S. (2002), 'Research with children: The same or different from research with adults?'. Childhood, 9(3), 321-341.

Suinn, R., (2006), 'Preface', in Trimble, J.E., and Fisher, C.,B (Eds.) The Handbook of Ethical Research with Ethnocultural Populations \& Communities, Thousand Islands: Sage.

Thomson, P. (Ed.). (2009), Doing visual research with children and young people. London: Routledge.

United Nations Committee on the Rights of the Child, (2009), General Comment no. 12, The Rightof the Child to be Heard (CRC/C/GC/12), http://www.refworld.org/docid/4ae562c52.html, accessed 17/10/14

Wetton, N. (1999), Draw and Write. Health Education Unit. Southampton: University of Southampton. 


\section{To cite this article:}

Heal, J.F. (2015). Research with school students: four innovative methods used to explore effective teaching. Exchanges: The Warwick Research Journal, 2(2), 263-276. Retrieved from:

http://exchanges.warwick.ac.uk/index.php/exchanges/article/view/63 